\title{
Simple method for lowering poly(methyl methacrylate) surface energy with fluorination
}

\author{
Kaya Tokuda, Tomoya Ogino, Masaru Kotera and Takashi Nishino
}

A poly(methyl methacrylate) (PMMA) surface was fluorinated by immersion in 3-(perfluoro-7-methyloctyl)-1,2-epoxypropene and subsequent heat treatment at $120^{\circ} \mathrm{C}$. The water contact angle on PMMA increased from $67^{\circ}$ to $111^{\circ}$ after the fluorination treatment with no loss of optical transparency. This high contact angle corresponds to a surface free energy of $10 \mathrm{~mJ} \mathrm{~m}^{-2}$, which is much lower than that of poly(tetrafluoroethylene) $\left(22 \mathrm{~mJ} \mathrm{~m}^{-2}\right)$. X-ray photoelectron spectroscopy analysis revealed that the surface was almost completely covered by fluoroalkyl groups, which imparted high hydrophobicity. This simple fluorination method effectively lowers the surface free energy of PMMA. The fluorinated PMMA also demonstrated low albumin adsorption, low blood clotting and antifouling properties against fingerprints. These characteristics reveal that fluorinated PMMA generated by a simple immersion treatment could serve as an antithrombogenic or antifingerprint fouling material.

Polymer Journal (2015) 47, 66-70; doi:10.1038/pj.2014.91; published online 5 November 2014

\section{INTRODUCTION}

Controlled surface properties are required for high performance of a number of products, including adhesives, paints and biomaterials. Many studies have been performed to generate hydrophilic surface modification of polymers by acid, alkali, ${ }^{1-3}$ plasma and corona treatments. ${ }^{4,5}$ However, a hydrophobic surface with low free energy would be useful for achieving various properties, such as lubricity, biocompatibility, controlled release, and durability. ${ }^{6-9}$

The fluorine atom is very effective for production of low free-energy surfaces because it possesses high electron negativity and a small atomic radius; therefore, fluorine forms a stable covalent bond with carbon. ${ }^{10}$ Poly(tetrafluoroethylene) (PTFE), a highly fluorinecontaining polymer, is widely utilized in fields such as coating engineering, biomaterials, soilresistance and breathable textiles because of its high water and oil repellency, organic solvent resistance and lubricity. However, the use of fluorine-containing polymers is limited by their mechanical properties. For example, PTFE requires processing by sintering powder at high pressure and temperature. Ideally, for surface fluorination, polymeric materials with low surface free energy $(\gamma)$ should be obtained without any changes in their bulk properties. When reactive functional groups are present on the surface, such as hydroxyl groups, a fluorinated coupling reagent reaction is effective. ${ }^{11,12}$ For example, hydroxyl groups on the surface of poly (vinyl alcohol) have been previously fluorinated using a fluorinated silane coupling agent, which resulted in a hydrophobic surface with a $\gamma$ of $10 \mathrm{~mJ} \mathrm{~m}^{-2}$. Durand et al..$^{13}$ reported hydrophobic silica surface formation by radical addition of tetrafluoroethylene. Nyström et al. ${ }^{14}$ reported that a super water repellent and self-cleaning cellulose surface were obtained through grafting of glycidyl methacrylate to hydroxyl groups and subsequent fluorination.
In this study, the surface of PMMA was fluorinated with a fluorinated reagent composed of glycidyl and perfluoroalkyl groups. The properties of the fluorinated PMMA were investigated, and its biocompatibility and antifouling properties against fingerprints were tested using albumin adsorption measurements, thrombogenesis studies and oleic acid wettability.

\section{MATERIALS AND METHODS}

\section{Sample preparation}

The PMMA used in these studies is commercially available Acrypet VH (kindly supplied by Mitsubishi Rayon Co. Ltd.). The number average molecular weight $\left(M_{\mathrm{n}}\right)$ and the polydispersity index $M_{\mathrm{w}} / M_{\mathrm{n}}\left(M_{\mathrm{w}}\right.$ : weight average molecular weight) measured using gel permeation chromatography were 76000 and 3.1, respectively. PMMA was purified twice by reprecipitation from an acetone solution into 10 volumes of methanol. PMMA films were cast onto a poly (ethylene) sheet from a $0.05 \mathrm{~g} \mathrm{ml}^{-1}$ chloroform solution at room temperature (thickness: $45 \mu \mathrm{m}$ ). The cast films were dried in air for $24 \mathrm{~h}$ and under vacuum at $40{ }^{\circ} \mathrm{C}$ for 1 day. PMMA films were rinsed with cyclohexane for $5 \mathrm{~min}$ after immersion in 3-(perfluoro-7-methyloctyl)-1, 2-propeneoxide (Scheme 1: Wako Pure Chemical Industries, Ltd., Osaka, Japan) for $30 \mathrm{~min}$ at $25^{\circ} \mathrm{C}$. Then, the films were air dried and heat-treated at $120^{\circ} \mathrm{C}$ for 1 day.

\section{Characterization}

$\mathrm{X}$-ray photoelectron spectroscopy (XPS) measurements were performed with a Shimadzu ESCA-850 to investigate the surface composition and bindings. The film surfaces were irradiated with $\mathrm{Mg}-\mathrm{K} \alpha$ radiation, generated at $8 \mathrm{kV}, 30 \mathrm{~mA}$ and then XPS spectra were collected at $90^{\circ}$ of the take-off angle between the sample and the analyzer. The pressure in the instrumental chamber was $<1.0 \times 10^{-5} \mathrm{~Pa}$. No radiation damage occurred during the data collection.

The dynamic contact angles of distilled water and diiodomethane were evaluated at room temperature. ${ }^{15-17}$ The advancing contact angle $\left(\theta_{\mathrm{a}}\right)$ and the 
receding contact angle $\left(\theta_{\mathrm{r}}\right)$ were measured when the droplet enlarged $(<2 \mathrm{~mm}$ diameter) and shrunk, respectively. The average contact angle $\left(\theta_{\mathrm{av}}\right)$ was calculated as:

$$
\theta_{\mathrm{av}}=\cos ^{-1}\left\{(1 / 2)\left(\cos \theta_{\mathrm{a}}+\cos \theta_{\mathrm{r}}\right)\right\} .
$$

The surface free energy $\left(\gamma_{s}\right)$ of the polymer solid was calculated from the contact angle values using Equations (2) and (3), which were proposed by Owens and Wendt ${ }^{17}$ in an extension of the Fowkes' concept: ${ }^{18}$

$$
\gamma_{\mathrm{s}}^{\mathrm{d}}+\gamma_{\mathrm{s}}^{\mathrm{p}}=\gamma_{\mathrm{s}}
$$

$$
(1+\cos \theta) \gamma_{1}=2\left(\gamma_{s}^{\mathrm{d}} \gamma_{1}^{\mathrm{d}}\right)^{1 / 2}+2\left(\gamma_{s}^{\mathrm{p}} \gamma_{1}^{\mathrm{p}}\right)^{1 / 2},
$$

where $\gamma_{l}$ is the surface free energy of the liquid, and $\gamma_{1}^{\mathrm{d}}$ and $\gamma_{1}^{\mathrm{p}}$ are its dispersion and polar components, respectively. The $\gamma_{1}^{\mathrm{d}}$ and $\gamma_{1}^{\mathrm{p}}$ values of water are 21.8 and $51.0 \mathrm{~mJ} \mathrm{~m}^{-2}$, respectively, and those of diiodomethane are 48.5 and $2.3 \mathrm{~mJ} \mathrm{~m}^{-2}$, respectively. ${ }^{17}$ To evaluate $\gamma_{\mathrm{s}}$ from the contact angles, several equations have been proposed. In this study, we employed the Young-Owens equation to simplify the evaluation, because the polar component contribution was negligibly small relative to the total $\gamma_{s}$ value, as shown below. The static contact angle of oleic acid was also measured at room temperature to estimate surface antifouling properties against fingerprints.

To estimate the stability of the fluorinated PMMA surface in hot water, the sample was immersed in distilled water at $50^{\circ} \mathrm{C}$ for 4 days. Then the static contact angle of water was measured on the surface.

Bovine serum albumin (Sigma-Aldrich Co., St Louis, MO, USA) was used to assess protein adsorption on the fluorinated PMMA surface. First, the films were immersed in a BSA solution $\left(2 \mathrm{mg} \mathrm{ml}^{-1}\right.$ in phosphate-buffered saline) for $24 \mathrm{~h}$ at $37^{\circ} \mathrm{C}$. Then, they were rinsed three times with phosphate-buffered saline to remove weakly adsorbed proteins. The amount of adsorbed albumin on the film surface was assessed using the bicinchoninic acid method, ${ }^{19}$ wherein the absorbance change of the solution at $562 \mathrm{~nm}$ was measured using a UV-vis spectrophotometer (Hitachi Ltd., U-2000). The amounts of albumin adsorbed on PMMA, PTFE, poly(urethane) (Nissho, Pellethane 2363-91AE), and poly(ethylene terephthalate) (PET) films were measured as references. In addition, the fluorinated films were immersed in distilled water at $37^{\circ} \mathrm{C}$ for a prescribed time period to estimate the stability of the fluorinated PMMA surface in water.

Square films $\left(1 \times 1 \mathrm{~cm}^{2}\right)$ of fluorinated PMMA, PMMA and PTFE were immersed in fresh human whole blood for $20 \mathrm{~min}$ and then rinsed with phosphate-buffered saline three times to remove weakly attached clots. Then,

$$
\left(\mathrm{CF}_{3}\right)_{2} \mathrm{CF}\left(\mathrm{CF}_{2}\right)_{6}-\underbrace{\mathrm{CH}}_{0}-\mathrm{CH}_{2}
$$

Scheme 1 Chemical formula of 3-(perfluoro-7-methyloctyl)-1, 2-propeneoxide. the films were immersed in a glutaraldehyde solution (Nacalai Tesque Inc., Kyoto, Japan) at $37^{\circ} \mathrm{C}$ for $24 \mathrm{~h}$ to fix attached clots on the surface. After $24 \mathrm{~h}$, the films were observed using an optical microscope (Nikon Co., Tokyo, Japan, E950). Fresh human whole blood supplied from a health donor was collected at the medical center for student health at Kobe University. All samples were obtained in accordance with ethical committee regulations of Kobe University.

\section{RESULTS AND DISCUSSION}

\section{Fluorinated PMMA surface}

Figure 1 shows the XPS $\mathrm{C}_{1 \mathrm{~s}}$ core level spectra of the PMMA and fluorinated PMMA films. The $\mathrm{C}_{1 \mathrm{~s}}$ spectrum for the fluorinated PMMA surface can be resolved into five peaks: at $294.1 \mathrm{eV}\left(-\mathrm{CF}_{3}\right), 291.8 \mathrm{eV}$ $\left(-\mathrm{CF}_{2}-\right), 288.8 \mathrm{eV}(-\mathrm{C}=\mathrm{O}), 286.5 \mathrm{eV}(\mathrm{C}-\mathrm{O})$ and $285.0 \mathrm{eV}\left(-\mathrm{CH}_{\mathrm{n}}\right) . \mathrm{In}$ contrast, the $\mathrm{C}_{1 \mathrm{~s}}$ spectrum for the PMMA surface has no peaks assigned to the perfluoroalkyl groups $\left(-\mathrm{CF}_{2}-\right.$ and $\left.-\mathrm{CF}_{3}\right)$. After fluorination, the $\mathrm{O} / \mathrm{C}$ ratio had reduced from 0.43 to 0.27 . These results confirm that fluorine-containing groups were successfully introduced onto the PMMA surface.

PMMA surfaces do not intrinsically possess any functional groups that can be reacted with the glycidyl groups of fluorinated reagents. However, the methoxycarbonyl groups of PMMA can change slightly to carboxylic acid. ${ }^{20}$ Thus, it is assumed that trace carboxylic acid has a role in the surface reaction. One of the plausible fluorination mechanisms of PMMA through the reaction between PMMA and glycidyl groups is as follows:

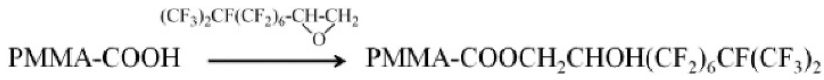

Figure 2 shows photographs of water droplets on PMMA and fluorinated PMMA films. The PMMA surface clearly became water repellent by simple immersion in the fluorinated reagent and subsequent heat treatment. The photographs superimposed on the upper-right corners demonstrate that the high optical transparency of PMMA was maintained after fluorination.

Table 1 lists the dynamic contact angles and the surface free energies of the PMMA and fluorinated PMMA films. The $\theta_{\mathrm{av}}$ value of water on the PMMA film was increased from $67^{\circ}$ to $111^{\circ}$, and the $\gamma_{\mathrm{s}}$ value decreased from $42.8 \mathrm{~mJ} \mathrm{~m}^{-2}$ to $10.0 \mathrm{~mJ} \mathrm{~m}^{-2}$ after fluorination. The low $\gamma_{\mathrm{s}}$ value after fluorination corresponds to almost complete coverage of the PMMA surface with fluorine components, as confirmed by XPS measurements. Moreover, the surface free energy of $10 \mathrm{~mJ} \mathrm{~m}^{-2}$ achieved using this fluorination technique is much lower than that of other hydrophobic polymers, such as poly(ethylene) a

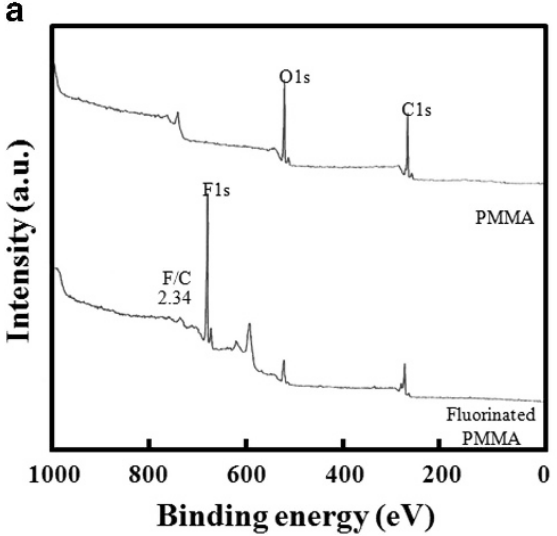

b

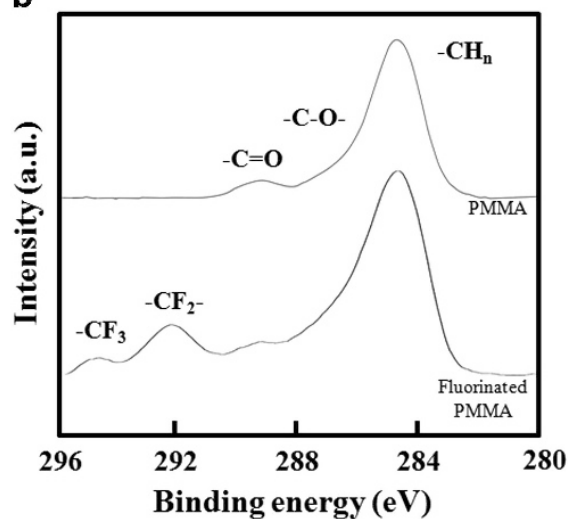

Figure $1 \mathrm{XPS} \mathrm{C}_{1 \mathrm{~s}}$ core level spectra of PMMA and fluorinated PMMA. Incident angle of X-ray is $90^{\circ}$. 

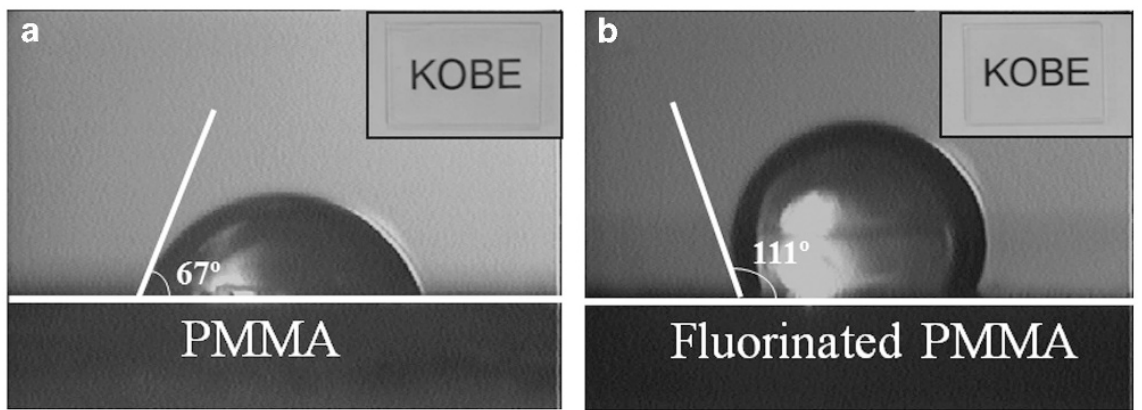

Figure 2 Photographs of water droplets on (a) PMMA and (b) fluorinated PMMA. Film transparency is shown in the upper-right corners.

Table 1 Contact angle $(\theta)$ and surface free energy $(\gamma)$ of PMMA and fluorinated PMMA films

\begin{tabular}{|c|c|c|c|c|c|c|c|c|c|c|c|}
\hline \multirow[b]{3}{*}{ PMMA } & \multicolumn{4}{|c|}{$\begin{array}{c}\text { Contact angle of water } \\
\text { (degree) }\end{array}$} & \multicolumn{4}{|c|}{$\begin{array}{l}\text { Contact angle of } \\
\mathrm{CH}_{2} \mathrm{I}_{2} \text { (degree) }\end{array}$} & \multirow{2}{*}{$\gamma_{s}^{d}$} & \multirow{2}{*}{$\frac{\gamma_{s}^{p}}{\left.n J m^{-2}\right)}$} & \multirow{2}{*}{$\gamma_{s}$} \\
\hline & $\theta_{\mathrm{av}}$ & $\theta_{\mathrm{a}}$ & $\theta_{\mathrm{r}}$ & $\Delta \theta$ & $\theta_{\mathrm{av}}$ & $\theta_{\mathrm{a}}$ & $\theta_{\mathrm{r}}$ & $\Delta \theta$ & & & \\
\hline & 67 & 75 & 56 & 19 & 43 & 47 & 39 & 8 & 30.9 & 11.9 & 42.8 \\
\hline $\begin{array}{l}\text { Fluorinated } \\
\text { PMMA }\end{array}$ & 111 & 121 & 101 & 20 & 99 & 108 & 90 & 18 & 7.4 & 2.6 & 10.0 \\
\hline
\end{tabular}

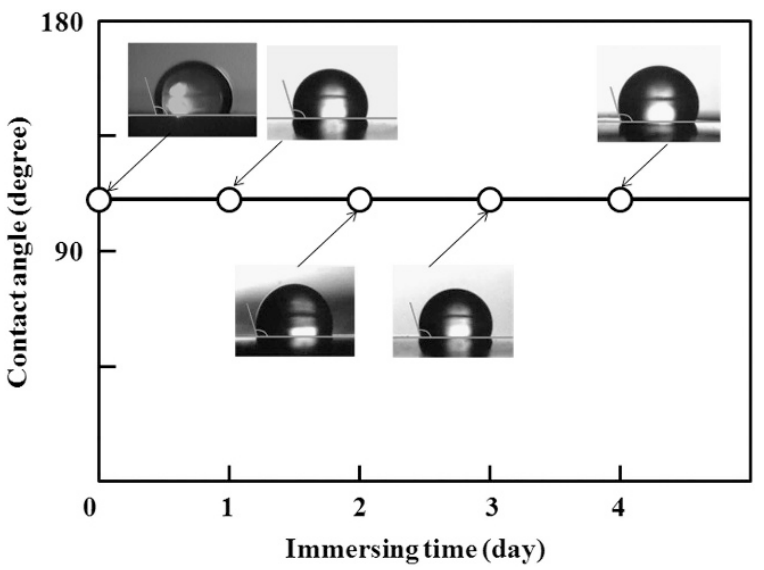

Figure 3 Contact angle of water on fluorinated PMMA after immersion in distilled water at $50^{\circ} \mathrm{C}$ for $1,2,3$ and 4 days. A full color version of this figure is available at the Polymer Journal online.

$\left(36 \mathrm{~mJ} \mathrm{~m}^{-2}\right)$, poly(propylene) $\left(32 \mathrm{~mJ} \mathrm{~m}^{-2}\right)$ and PTFE $\left(22 \mathrm{~mJ} \mathrm{~m}^{-2}\right) .{ }^{15}$ The fluorinated PMMA in this study showed higher water repellency than that achieved with other hydrophobizing methods, such as plasma treatment followed by fluorination with a silane-coupling treatment. ${ }^{14,21}$ In contrast, the value is much higher than that achieved with $-\mathrm{CF}_{3}$ groups with a hexagonally close-packed surface (6.7 $\mathrm{mJ} \mathrm{m}^{-2}$ ), which was reported as the lowest surface free energy of any solid at room temperature. ${ }^{16}$ This difference occurred because $-\mathrm{CF}_{2}-$ groups $\left(\gamma: 18 \mathrm{~mJ} \mathrm{~m}^{-2}\right)^{22}$ were exposed on the surface in addition to $-\mathrm{CF}_{3}$ groups, similarly to what is observed for the random copolymer of methyl methacrylate and perfluorinated methacrylate. ${ }^{23,24}$

Figure 3 displays the static contact angle of distilled water on the fluorinated PMMA after immersion in distilled water at $50{ }^{\circ} \mathrm{C}$ for

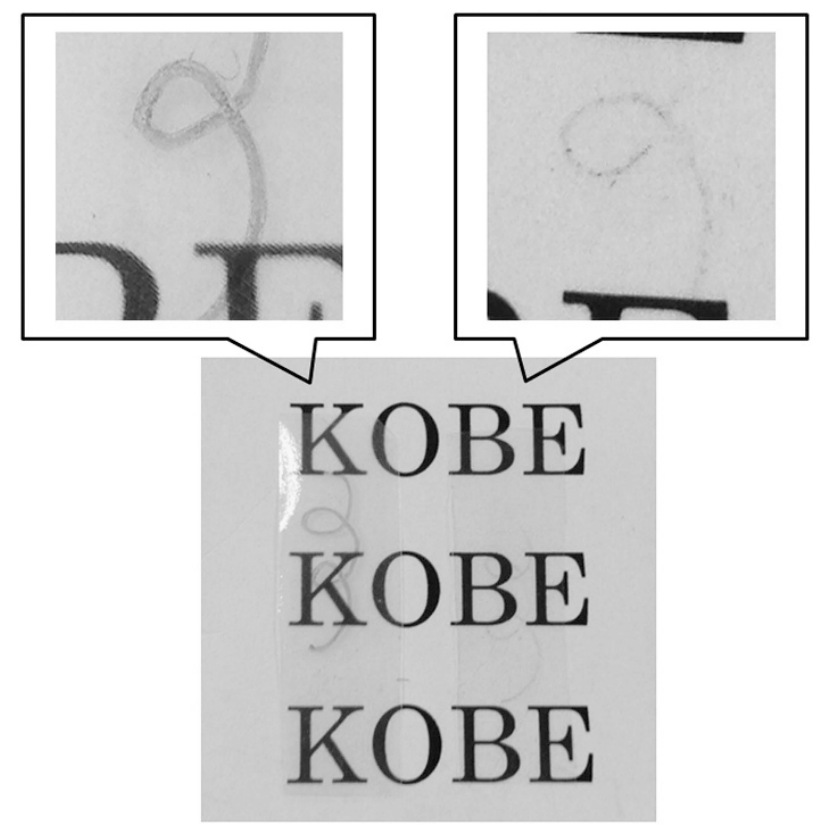

Figure 4 Photographs of (left) PMMA and (right) fluorinated PMMA films. Lines drawn with permanent marker. A full color version of this figure is available at the Polymer Journal online.

designated time periods. Even after 4 days, the static contact angle of distilled water was maintained at $112^{\circ}$. It is very difficult to show direct evidence of covalent bonding of the reagent to the surface; however, the results in Figure 3 indicate that the fluorinated PMMA coating is stable under heat and under wet conditions.

\section{Applications of fluorinated PMMA}

Figure 4 shows photographs of PMMA and fluorinated PMMA films with lines drawn with a permanent marker. Unlike the original PMMA surface, the oily felt pen resin was repelled on the fluorinated PMMA surface.

Figure 5 displays a droplet of oleic acid on PMMA films before and after fluorination. Oleic acid is the main component of sebum. The contact angle of oleic acid on the PMMA films was markedly increased from $16^{\circ}$ to $82^{\circ}$ by fluorination. The results in Figures 4 and 5 indicate that the fluorinated surface has antifouling properties and could potentially be utilized in antifingerprint applications.

Figure $6 \mathrm{a}$ shows the amount of albumin adsorbed onto various polymer films. Tamada and $\mathrm{Ikada}^{25}$ reported that protein adsorption was reduced on very hydrophobic surfaces. In comparison with 

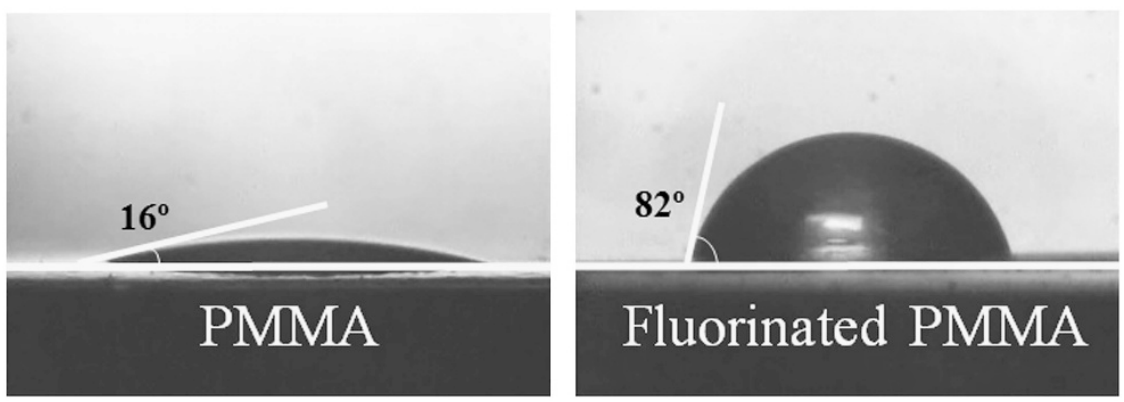

Figure 5 Photographs of oleic acid droplets on (left) PMMA and (right) fluorinated PMMA films. A full color version of this figure is available at the Polymer Journal online.

a

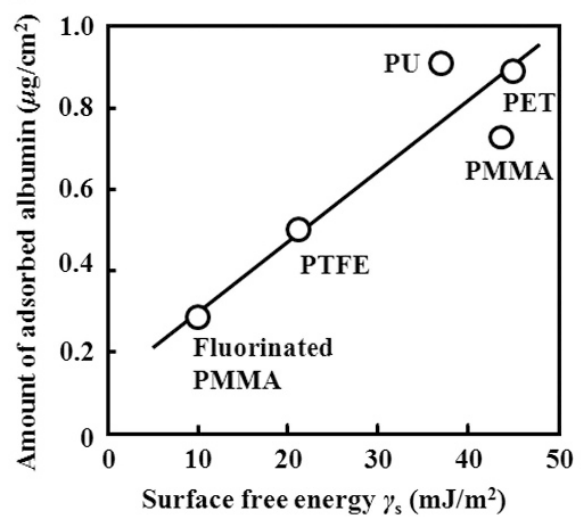

b

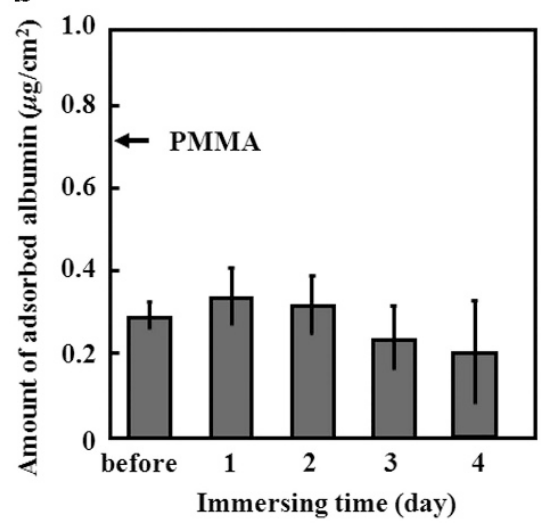

Figure 6 (a) Amount of albumin adsorbed on various polymer surfaces. PET, poly(ethylene terephthalate); PTFE, poly(tetrafluoroethylene); PU, poly(urethane). (b) Amount of albumin adsorbed on fluorinated PMMA surfaces before and after immersion in water for several days. Amount of albumin adsorbed on PMMA surface was superimposed on the figure with the arrow. A full color version of this figure is available at the Polymer Journal online.

conventional hydrophobic polymers, such as PTFE, poly(urethane), poly(ethylene terephthalate) and PMMA, the fluorinated PMMA surface showed reduced albumin adsorption. This result is in accordance with Tamada and Ikada's observation, that is, low $\gamma$ values impart high protein repellency to surfaces.

Figure $6 \mathrm{~b}$ shows the amount of albumin adsorbed on fluorinated PMMA surfaces before and after immersion in water at $37^{\circ} \mathrm{C}$ for several days. The low albumin adsorption on fluorinated PMMA was maintained even after 4 days of immersion in water. This result confirmed that the protein repellency of the fluorinated film is stable in water.

Figure 7 shows photographs of PMMA, PTFE and fluorinated PMMA films after immersion in human whole blood and subsequent rinsing. On PMMA and PTFE films, adhered clotting was observed over the entire surfaces. Whereas no apparent clotting occurred on the right side of the PMMA film, visible blood clots formed and localized on the left side. By contrast, blood on the fluorinated PMMA film was easily removed by rinsing, resulting in no observable clots. This antithrombogenicity originated from the protein repellent characteristics of the fluorinated PMMA surface. When synthetic materials come into contact with blood, proteins rapidly adsorb onto their surfaces, which triggers clotting. Platelet adhesion and subsequent clotting are inhibited on surfaces with resistance to protein adsorption. ${ }^{26,27}$ Thus, this result exhibits that the fluorinated PMMA has weak platelet affinity and is a good candidate for use as an antithrombogenic material.

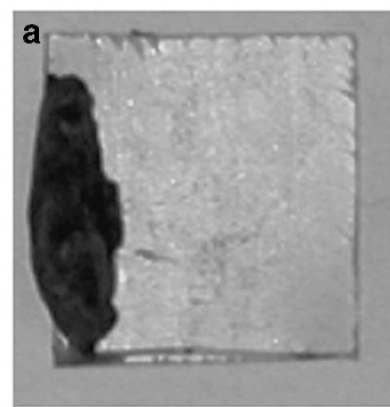

PMMA

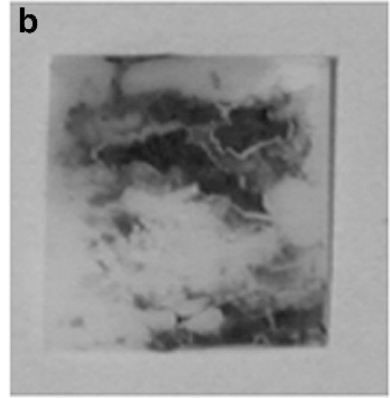

PTFE

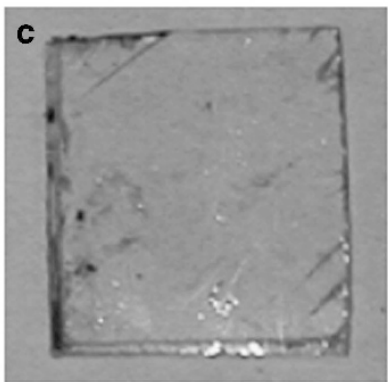

Fluorinated PMMA

Figure 7 Photographs of (a) PMMA, (b) PTFE and (c) fluorinated PMMA films after immersion in whole blood for $20 \mathrm{~min}$ at $37^{\circ} \mathrm{C}$. A full color version of this figure is available at the Polymer Journal online. 


\section{CONCLUSIONS}

PMMA surfaces were fluorinated by simple immersion in a fluorinated reagent and subsequent heat treatment. The contact angle of water on the PMMA increased to $111^{\circ}$ after fluorination, which corresponds to a surface free energy of $10 \mathrm{~mJ} \mathrm{~m}^{-2}$. This surface free energy is much lower than that of PTFE and is stable under wet/heat conditions. In addition, the fluorinated PMMA surface demonstrated high resistance to albumin adsorption and thrombogenesis, as well as antifouling properties against fingerprints. This fluorination technique simply and effectively lowers the surface free energy of PMMA.

1 Sogiv, J. Organized monolayers by adsorption I. formation and structure of oleophobic mixed monolayers on solid surfaces. J. Am. Chem. Soc. 102, 92-98 (1980).

2 Tillman, N., Ulman, A., Penner, T. L. Formation of multilayers by self-assembly. Langmuir 5, 101-111 (1989).

3 Wasserman, S. R., Tao, Y. T., Whitesides, G. M. Structure and reactivity of alkylsiloxane monolayers formed by reaction of alkyltrichlorosilanes on silicon substrates. Langmuir 5, 1074-1087 (1989)

4 Terlingen, J. G. A., Takens, G. A. J, Van Dei Gaag, F. J., Hoffman, A. S., Feijen, J. On the effect of treating poly(acrylic acid) with argon and tetrafluoromethane plasmas: kinetics and degradation mechanism. J. Appl. Polym. Sci. 52, 39-53 (1992).

5 Terlingen, J. G. A., Hoffman, A. S., Feijen, J. Effect of glow discharge treatment of poly (acrylic acid) preadsorbed onto poly(ethylene). J. Appl. Polym. Sci. 50, 1529-1539 (1994).

6 Park, D., Weinman, C. J., Finlay, J. A., Fletcher, B. R., Paik, M. Y., Sundaram, H. S., Dimitriou, M. D., Sohn, K. E., Callow, M. E., Callow, J. A., Handlin, D. L., Willis, C. L., Fischer, D. A., Kramer, E. J., Ober, C. K. Amphiphilic surface active triblock copolymers with mixed hydrophobic and hydrophilic side chains for tuned marine fouling-release properties. Langmuir 26, 9772-9781 (2010).

7 Kessman, A. J., Cairns, D. R. Microtribological study of internal surfaces of fluorinated mesoporous silica films. Langmuir 27, 5968-5975 (2011).

8 Booth, B. D., Vilt, S. G., Lewis, J. B., Rivera, J. L., Buehler, E. A., McCabe, C., Jennings, G. K. Tribological durability of silane monolayers on silicon. Langmuir 27 5090-5917 (2011).

9 Klein, R. J., Fischer, D. A., Lenhart, J. L. Thermal and mechanical aging of selfassembled monolayers as studied by near edge X-ray absorption fine structure. Langmuir 27, 12423-12433 (2011).

10 Zisman, W. A. Relation of the equilibrium contact angle to liquid and solid constitution. Adv. Chem 43, 1-51 (1964).
11 Guo, Y., Di, C., Liu, H., Zheng, J., Zhang, L., Yu, G., Liu, Y. General route toward Patterning of graphene oxide by a combination of wettability modulation and spincoating. ACS NANO 4, 5749-5754 (2010).

12 Nishino, T., Meguro, M., Nakamae, K. Poly(vinyl alcohol) with low surface free energy by fluorination. Int. J. Adhes. 19, 399-403 (1999).

13 Durand, N., Gaveau, P., Silly, G., Améduri, B., Boutevin, B. Radical grafting of tetrafluoroethylene and vinylidene fluoride telomers onto silica bearing vinyl groups. Macromolecules 44, 6249-6257 (2011).

14 Nyström, D., Lindqvist, J., Őstmark, E., Antoni, P., Carlmark, A., Hult, A., Malmström, E. Superhydrophobic and self-cleaning bio-fiber surfaces via ATRP and subsequent postfunctionalization. ACS Appl. Mater. Interfaces 1, 816-823 (2009).

15 Sumiya, K., Taii, T., Nakamae, K., Matsumoto, T. Adhesion of the vacuum-deposited cobalt thin films to polymer films. J. Adhes. Soc. Jpn. 18, 345-351 (1982).

16 Nishino, T., Meguro, M., Nakamae, K., Matsushita, M., Ueda, Y. The lowest surface free energy based on - $-F_{3}$. Langmuir 15, 4321-4323 (1999).

17 Owens, D. K., Wendt, R. C. Estimation of the surface free energy of polymers. J. Appl. Polym. Sci. 13, 1741-1747 (1969).

18 Fowkes, S. M. Additivity of intermolecular forces at interfaces. I. determination of the contribution to surface and interfacial tensions of dispersion forces in various liquids. J. Phys. Chem. 67, 2538-2541 (1963).

19 Smith, P. K., Krohn, R. I., Hermanson, G. T., Mallia, A. K., Gartner, F. H., Provenzano, M. D., Fujimoto, E. K., Geoke, N. M., Olson, B. J., Klenk, D. C. Measurement of protein using bicinchoninic acid. Anal. Biochem. 150, 76-85 (1985).

20 McCarley, R. L., Vaidya, B., Wei, S., Smith, A. F., Patel, A. B., Feng, J. Resist-free patterning of surface architectures in polymer-based microanalytical devices. J. Am. Chem. Soc. 127, 842-843 (2005).

21 Tsougeni, K., Tserepi, A., Constantoudis, V., Gogolides, E. Plasma nanotextured PMMA surfaces for protein arrays: increased protein binding and enhanced detection sensitivity. Langumuir 26, 13883-13891 (2010).

22 Hare, E. F., Shafrin, E. G., Zisman, W. A. Properties of films of adsorbed fluorinated acids. J. Phys. Chem. 58, 236-239 (1954).

23 Nishino, T., Urushihara, Y., Meguro, M., Nakamae, K. Surface properties and structures of diblock and random copolymers with perfluoroalkyl side chains. J. Colloid Interface Sci. 279, 364-369 (2004).

24 Urushihara, Y., Nishino, T. Effects of film forming conditions on surface properties and structures of diblock copolymer with perfluoroalkyl side chains. Langmuir 21 2614-2618 (2005).

25 Tamada, Y., Ikada, Y. Effect of preadsorbed proteins on cell adhesion to polymer surface. J. Colloid Interface Sci. 155, 334-339 (1993).

26 Tanaka, M., Motomura, T., Kawada, M., Anzai, T., Kasori, Y., Shiroya, T., Shimura, K. Onishi, M., Mochizuku, A. Blood compatible aspects of poly(2-methoxyethyl acrylate) (PMEA)-relationship between protein adsorption and platelet adhesion on PMEA surface. Biomaterials 21, 1471-1481 (2000).

27 Vroman, L.. Adams, A. L. Identification of rapid changes at plasma-solid interfaces. J. Biomed. Mater. Res. 3, 43-67 (1969). 